\title{
Discussion of Energy Saving Technique Scheme for Rail Electromechanical Equipment System
}

\author{
Yue Xingzuo and Wu Lei ${ }^{*}$ \\ Wuhan institute of shipbuilding technology Wuhan china \\ 84771162@qq.com
}

Keywords: Rail; Electromechanical system; Energy saving technique

\begin{abstract}
Due to the growing energy shortage and the sustained rapid growth of the national economy, energy conservation has become one of the most concerned issues in the society. Rail transit is a large energy consumer with great energy saving potential. This paper analyzes the electrical load and energy usage characteristics of rail transit. This paper reviews the energy-saving technologies of electromechanical equipment systems and discusses the application of renewable energy in rail transit. The research results can guide the design, construction and operation of rail transit in China, reduce the overall energy consumption of rail transit and reduce expenditure.
\end{abstract}

\section{Introduction}

With the development of urbanization in China, the city is constantly expanding, and the urban population is rapidly increasing, making the city's traffic problems more prominent. In order to solve the traffic problem, many cities in China pay attention to the construction of ground rail transit and underground rail transit. By the end of 2014, 95 subways had been built in 22 cities across the country, with a mileage of 2,900 kilometers. By 2020, China's rail transit investment will exceed 1 trillion yuan.

Although the energy consumption of rail transit is smaller than that of other forms of transportation according to the same transport capacity, due to the characteristics of its large volume, the total power consumption is quite large, so it is a large energy consumer. Therefore, the energy conservation and emission reduction work of urban rail transit is very important.

With the support of related topics, this paper reviews the energy-saving technologies of metro electromechanical systems and forms a basic application scheme for energy-saving technologies of rail transit electromechanical systems.

\section{Analysis of Rails' Power Load}

There are two main types of rail traffic load: traction power load and electrical equipment system power load.

Electromechanical systems include environmental control systems, low voltage distribution systems, escalators and elevator systems, weak current control systems, screen door systems, water supply and drainage systems and others. It can be known from the literature [1] that the environmental control system, escalator/elevator system and low-voltage power distribution system account for more than $90 \%$ of the total system power consumption. Therefore, this paper focuses on the environmental control system and lighting system.

\section{System Energy-saving Technology for Rail Transit Electromechanical Equipment}

\section{Energy-saving Technology of Environmental Control System}

The subway environmental control system, also known as the subway ventilation and air conditioning system, is an important part of the subway project. The environmental control system can create a comfortable and safe riding environment for passengers, but at the same time its energy consumption is also becoming more and more prominent. 
For the subway environmental control system, in order to reduce the air conditioning load, the following energy-saving technologies can be adopted:

1) Installation of Long Air Duct and Uniform Air Duct Component

Air conditioning air systems are an important part of air conditioning systems. Long air ducts are often used in air-conditioning systems in public areas of metro stations. The reasonable distribution of air-conditioning system air volume is directly related to the comfort of public areas and affects the energy consumption of wind turbines ${ }^{[2]}$. The traditional method of adjusting the airflow section such as the cross-sectional area of the duct is difficult to adjust, the effect is poor, and the pipe is wasted.

In 2010, Wu Xiping developed a new type of long air duct and air return device. The device converts the distribution of air flow in the traditional three-way pipe from static to full pressure of the air flow, and provides basis and guarantee for the intuitive distribution of the air volume of the three-way; The device adds a drainage pipe in the three-way main pipe, so that the distribution and flow direction of the airflow in the two pipes is more reasonable, the airflow disturbance is reduced, and the resistance coefficient of the three-way valve is reduced. It can be seen from the actual engineering measurement that after the installation of the device, the air outlet adjusting device of different air outlets under the variable frequency condition of the fan can fully meet the adjustment requirements of uniform air supply ${ }^{[3]}$.

In addition, in 2014, Liu Jun et al. proposed an embedded flow regulating duct member. The component can be directly embedded in the main air duct, and the installation process is simple, and the loading and unloading is convenient. The experimental results show that when the fan is running at $10 \sim 50 \mathrm{~Hz}$, the airflow imbalance rate of most of the air outlets is kept within $5 \%$, and the error is small. The air supply volume can be evenly distributed. The device can maintain good air distribution uniformity and reduce the adjustment workload. It is suitable for the variable air volume air conditioning system of the subway. The structure diagram is shown in Figure P.

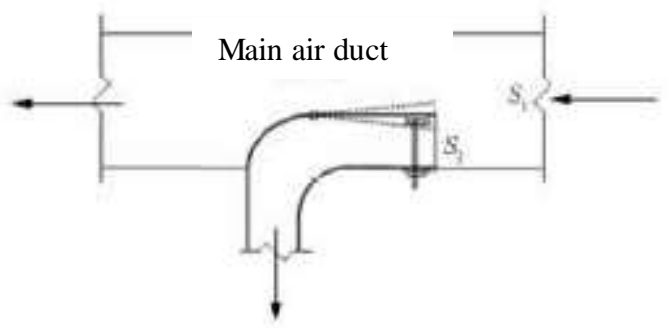

Figure 1 Schematic Diagram of Embedded Force Regulating Air Duct Components

2) Rational Use of Piston Ventilation

In open systems and screen door systems, the piston air can be ventilated to remove residual heat and residual moisture: In the closed system, the piston wind can carry a part of the station air-conditioning cold air into the tunnel to cool the air in the tunnel to ensure the normal operation of the vehicle air-conditioning equipment. In the tunnel ventilation design, the effective design and utilization of piston ventilation can meet the tunnel environment design requirements.

At present, there are single-piston wind shaft mode and double-piston wind shaft mode in the piston wind of domestic subway tunnel ventilation system. The research shows that in the natural ventilation system of the subway tunnel with the platform screen door, the ventilation efficiency when using the double wind well is far greater than that of the single wind well, and for the single piston wind well mode, the single wind well condition of the outbound end. The ventilation effect is slightly better than the inbound end condition.

But single-piston systems also have their own advantages. Since the subway tunnel ventilation system consists of air ducts and tunnel fans, the area of the subway station is about 1/4 of the total area of the station, and the construction and coordination of the ground piston wind pavilion is difficult. Therefore, a single piston system is a common system for reducing the size of a tunnel ventilation system.

3) Reasonable Configuration of Small Fresh Air Blowers 
The fresh air load is an important part of the subway load. Taking the street station of Wuhan Metro Line 2 as an example, this paper carries out load calculation analysis. It can be seen that 75 percent of the total load of the metro station is composed of personnel load and fresh air load, and the fresh air load has obvious time-varying characteristics.

The configuration of the small new fan belongs to the ventilation and air conditioning system of the public area of the subway. The calculation of the minimum fresh air volume of the air-conditioning in the public area of the metro station should be the maximum of the following three: the minimum fresh air volume of the passengers is $12.6 \mathrm{~m} 3 / \mathrm{h}: 10 \%$ of the total airflow of the air-conditioning: the air leakage of the screen door $(18 \% \sim 50 \%)$ : In actual operation, the air leakage of the screen door is alternating with the opening and closing of the screen door, and can only be calculated according to the hourly average air leakage amount; In the small traffic range, the air leakage of the shielding door often reaches more than $30 \%$ of the air conditioning cycle landscape. However, if the small new fan is equipped with the largest item, it is obviously too large, and the energy consumption of the new fan is significant. Therefore, the design of the small and medium-sized new fan can only be configured according to the former two. The insufficient fresh air is naturally infiltrated by the entrance and exit.

4) Frequency Conversion Operation of Exhaust Fan

The basic functions of the exhaust fan include: in normal operation, the tunnel temperature and fresh air ventilation requirements are met; when the train is blocked in the interval, the section is mechanically ventilated; in the interval fire, the longitudinal exhaust of the section is organized. The design period of rail transit is divided into initial (3 years), recent (10 years), and long-term (25 years); The long-term driving logarithm can generally reach 30 pairs/hour, but the initial stage is often only 12 pairs/hour; and the tunnel temperature is calculated according to the heat-dissipating fan capacity $(40 \sim 50 \mathrm{~m} 3 / \mathrm{s})$ that meets the long-term tunnel temperature. ), there is a large surplus in the initial and recent years. In the design, it is recommended that the exhaust fan adopts a simple and effective control scheme: the frequency setting operation corresponding to the driving logarithm, so as to achieve energy saving in the initial and recent operation.

5) Energy-saving Control of Station Air Conditioning Water System's Operation

The air conditioning water system uses the highest energy efficiency ratio to optimize the cluster control.

6) Variable Air Volume Control of Station Air Conditioning and Air System

The variable air volume system is an all-air system that adapts to room load changes by changing the scenery that is sent to the room, and it has good energy saving performance. Studies have shown that for the variable air volume system of the subway station, from the perspective of maintaining indoor temperature and energy saving, it is most appropriate to adopt the return air temperature control method. Taking the crab station of Wuhan Metro Line 2 as the analysis object, the simulation finally obtained the variable air volume system using the control method. The energy saving rate reached $67 \%$ and $55.9 \%$, respectively, without considering the condensation of the air supply and considering the condensation of the air supply ${ }^{[6]}$.

7) Use Direct Evaporative Air Conditioning System

The water-cooled screw machine has the advantages of small volume, light weight, stable operation, less wearing parts, high efficiency, large single-stage pressure ratio, stepless adjustment of energy and good matching of capacity and cooling load of the subway station. Therefore, it has become the first choice for underground station chillers. However, because the subway line often crosses the bustling area of the city, the cooling tower used with the screw machine, the noise floating water, the impact on the urban landscape, etc., the cooling tower setting problem often becomes a difficult point in the design of the subway station.

Evaporative cooling chillers can solve the above problems on the basis of reducing the total energy consumption of the refrigeration station. Evaporative cooling chillers are actually the combination of cooling towers and water-cooled chillers. The cooling principle is shown in Figure 2 . 


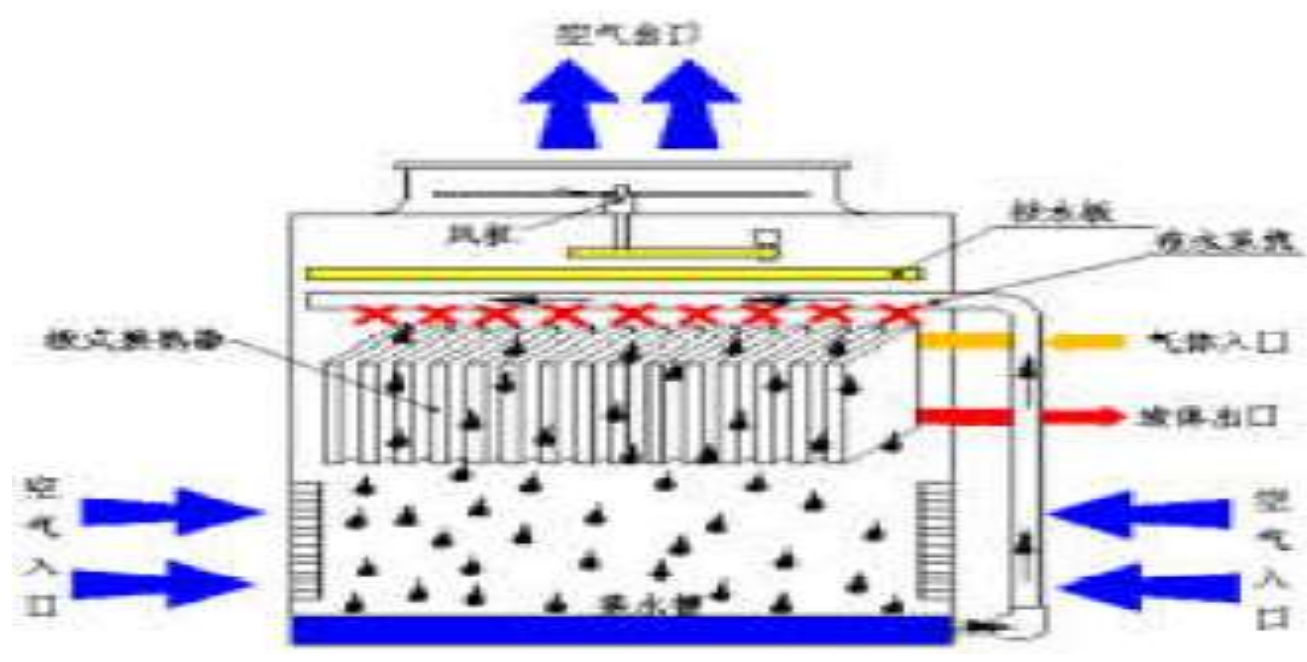

Figure 2 Refrigeration Principle Diagram of Evaporative Condensing Unit

This paper compares the schemes of four air-conditioning mainframes in the first phase of Wuhan Metro Line 6 project. The calculation shows that the four stations use evaporative cooling chillers. Except for Jianghan Road Station, the other three stations of the annual freezing station energy saving are: 47,000 yuan for Hanzheng Street Station, 48,000 yuan for Liuduqiao Station and 84,000 yuan for Dazhi Road Station. It can be seen from the analysis that when the evaporative cooling chiller is placed outdoors, there is no condensing exhaust fan, and there is no chiller in the underground. Compared with the traditional screw chiller, this has a considerable energy saving advantage, and saves the land area inside the station worth promoting.

8) Composite Screen Door is Used

The screen door is characterized by its safety, comfort, beauty and modernization, which can reduce the air conditioning load of the station. In the new subway, the composite screen door system is widely used. The venting port with the controllable damper is arranged on the upper part of the traditional screen door fixed door or sliding door. Compared with the traditional screen door, the composite screen door has the advantage of reliable natural ventilation during the season to maintain the subway environment and save ventilation energy.

In determining the setting scheme of the composite screen door system, the following several schemes should be considered from the aspects of structural load, sealing effect and operability: In the form of a perforated plate, the fixed door unit is divided into a fixed door plate and a sliding door plate, and the two are stacked and installed, and each has a plurality of holes or slits, and the connection and the partition of the station and the tunnel are realized by sliding the sliding door plate; In the multi-part opening form, the narrow louver tuyere is opened in the upper part and the lower part of the original screen door, and the platform end door is considered to be opened; only the upper opening form is opened in the longitudinal direction of the platform only at the top of the screen door. The research shows that the third scheme is the best, the tuyere height can be set to $0.4 \sim 0.6 \mathrm{~m}$, and the tuyere length should be less than the fixed gate length in the screen door, that is, less than $2.7 \mathrm{~m}{ }^{[7]}$.

\section{Energy-saving Technology for Lighting Systems}

The lighting system of the urban underground railway station has a long working time (the artificial lighting is also needed during the day), so the energy consumption is large, which makes the lighting energy saving of the subway station significant.

When designing lighting, firstly select the appropriate light source according to the characteristics of non-N light source and the design principle of subway lighting. The general lighting of the station hall, platform, office space, control room and the channel with a clear height below $4.5 \mathrm{~m}$ should be suitable. T8 or T5 straight tube fluorescent lamps and compact fluorescent lamps are used. Straight tube fluorescent lamps should be based on a color temperature of about $4000 \mathrm{~K}$, because such a variety of light sources, good light quality, closest to the natural state of the daytime, and thus most help to eliminate the feeling of depression and occlusion of the underground 
space. For the space with large net height, the metal halide lamp with less power of single lamp can be used. The guiding light and emergency lighting in the subway station can choose LED light source with higher luminous efficiency ${ }^{[8]}$.

Second, choose the right luminaire. The optical characteristics of the luminaire have three main technical parameters, namely, the light distribution curve, the efficiency of the luminaire, and the illuminating angle of the luminaire for the lighting of the subway station, in addition to its electrical safety performance, heat resistance and other standards. Light distribution curves and shading with space-compatible lighting features, the luminaire efficiency should be as high as possible [8].

At present, the popular practice in the market is to introduce contract energy management mechanisms for subway lighting fixtures under suitable conditions. The rail company adopts the contract energy management model to implement energy-saving renovation within the group company. Utilize the capital and technical advantages of energy-saving service companies to reduce the financial pressure of the group companies and the technical risks of energy-saving renovation, and improve the operational services and management level, so as to achieve the goal of energy saving. For example, the lighting system of the 5th section of the Beijing Metro Lines 1 and 2 has cooperated with the energy-saving company to carry out energy-saving renovation of green lighting based on contract energy management, with significant economic benefits and outstanding social benefits.

In addition, the subway lighting control system also has great energy saving potential. The lighting intelligent control system will adjust the lighting to the corresponding luminance according to the different passenger flow and the passenger comfort requirements according to the preset lighting grading. This can not only meet the lighting brightness requirements in the station, but also save energy. This paper takes the lighting control system of Wuhan Shilipu subway station as the research object, and designs an intelligent lighting control system according to the actual situation of the subway station. Through the calculation of the mathematical model, it can be found that the power of the intelligent control optimization can be saved by $18.4 \%$ compared with the optimization.

\section{Escalator}

The escalator adopts frequency conversion speed regulation technology, implements time-sharing management and automatic shifting, which can achieve the purpose of effective energy saving. In addition, flexible opening of the escalator is also an effective means of energy saving. During off-peak hours, some large subway stations with more than 2 escalators should be closed in time to save energy.

At the same time, whether the escalator is frequency-converted should be analyzed in combination with specific conditions. This paper finds in the investigation of Shanghai Metro Line 1 that the subway station has a large flow of people and the elevators are frequently used. The energy saving of the elevator frequency conversion system is not obvious. Therefore, it is not suitable to use the elevator frequency conversion system for large traffic stations.

\section{Renewable Energy Technology}

In the design of rail transit, it is possible to apply renewable energy technologies such as ground source heat pumps, solar photovoltaic power generation technologies, and solar thermal power generation technologies.

For example, in the application of ground source heat pump, Liu Silen et al. conducted a simulation analysis of a ground source heat pump system and a conventional chiller for a station in Wuhan, and analyzed the economic environment benefits. The results show that the use of the ground source heat pump system in the subway station in the hot summer and cold winter area can reduce the electricity consumption of the air conditioning system by $22.9 \%$ per year, and the annual operating investment cost savings of 19,700 yuan. At the same time, when the carbon trading mechanism is fully established, it has the potential to bring in a carbon trading income of 715,000 yuan per year [9].

In terms of photovoltaic power generation, this paper conducts a photovoltaic metro integrated design calculation for a large-scale light rail site in Wuhan. It can be seen that the total installed 
capacity of the photovoltaic system is $212.5 \mathrm{~kW}$, and the annual power generation of the system is $221,600 \mathrm{kWh}$.

Thermoelectric power generation uses the Seebeck effect to directly convert thermal energy into electrical energy. The heat generated by the temperature difference between high temperature and low temperature converts the moving thermal energy into electrical energy to generate electricity. Solar thermal power generation technology has many advantages, but due to the low energy density of solar energy itself, large fluctuations with time, power generation efficiency is easily interfered by solar radiation angle, etc., resulting in many disadvantages of solar thermal power generation technology in using solar energy. However, the microfluidic optical solar concentrating technology based on electro-wetting method in recent years has well compensated for these defects of solar thermal power generation system and laid the foundation for the popularization of solar thermal power generation.

Therefore, in some sites, such as depots, photovoltaic panels and solar thermal power generation devices can be installed in large quantities to compensate for site lighting and advertising light box power, and can be connected to the grid.

The above is the key energy-saving technical solutions proposed in this paper for the rail transit electromechanical equipment system. In addition, the temperature of the station hall and the train is reasonably set (the air conditioning temperature in the train is controlled at $25{ }^{\circ} \mathrm{C}$, the platform is $26 \sim 27{ }^{\circ} \mathrm{C}$, and the station hall is $27-30{ }^{\circ} \mathrm{C}$ ). Adopt effective pipeline insulation: scientifically arrange the operation of tunnel fans during maintenance period; set up energy management systems for stations, etc., are also applicable rail transit energy-saving technologies.

\section{Conclusion}

This paper first analyzes the load characteristics of the subway, and clarifies that the traction system and the environmental control system are the key energy-saving objects. Secondly, the energy-saving measures of the electromechanical equipment system are reviewed and analyzed: The energy-saving technical solutions for rail transit electromechanical systems include: uniform air supply from long air ducts, rational use of piston ventilation, rational allocation of small new wind turbines, and frequency conversion operation of exhaust heat fans: The energy-saving control of the station air-conditioning water system is carried out, and the variable air volume control of the station air-conditioning air system is adopted, and the direct-evaporation air-conditioning system is adopted, and the composite screen door is adopted. In terms of lighting, a suitable light source is selected and a contract energy management system is adopted. In the case of conditions, the intelligent lighting control system is designed; for the escalator, the frequency conversion technology should be adopted according to local conditions. For the station where the flow of people is always large, the ordinary elevator can be used, and the inverter elevator consumes energy.

In addition, rail transit is also suitable for the application of renewable energy technologies, combined with ground source heat pump technology, photovoltaic power generation technology, solar thermal power technology.

\section{Acknowledgement}

I would like to thank the Wuhan Metro Group for its strong support in the "Technology and Policy Research for Energy Efficiency Improvement in the Field of Metro Operation (WHRT-KY-201016)" project.

\section{References}

[1] Li Chao. Analysis of Bamboo Energy Design for Subway Power System[J].Railway Construction Technology, 2010, (Supplement): 148-152

[2]Liu Silun. Application of Ground Source Heat Pump in Metro Station in Hot Summer and Cold 
Winter Areas [D]. [D]. Wuhan: Wuhan University of Technology, 2014

[3] Wang Dong. Wu Xiping, Yu Henan. Application of a New Type of Uniform Air Supply Pipeline in Subway Environmental Control System[J].Building Energy Ventilation and Air Conditioning,2011,30(2): 72-75

[4] Ye Da fa, "Common energy saving methods and control for air conditioning systems ,",2012.

[5] Li Linlin. Analysis of Ventilation Single Piston System for Subway Engineering Tunnels[J]. Urban Rail Transit Research. 2014, 17(7): 112-114

[6] Liu Jun, Liu Jian, Che Lunfei. Research on Control Method of Air Conditioning Air Conditioning System in Subway[J]. Building Heat Ventilating and Air Conditioning, 2014. 33(5): 10-15

[7] Chen Yao. Study on Natural Ventilation Characteristics of Compound Screen Door Metro Station[D].Chengdu: Southwest Jiaotong University, 2013

[8] Gebreslassie, Berhane H, Medrano Marc. Optimum heat exchanger area estimation using coefficients of structural bonds: Application to an absorption chiller . International Journal of Refrigeration, 2010, 33:529-537.

[9] Hong Weipeng, Sun Yaobo. Application Research of EPON Technology in Highway Video Surveillance System[J].Highway.2010(I):102-105. 